Adrian F. Fernando, MD Brian Joseph dG. De Jesus, MD² Alejandro P. Opulencia, MD' Gil M. Maglalang, Jr., MD² Antonio H. Chua, MD ${ }^{1,3}$

'Department of Otorhinolaryngology Head and Neck Surgery

University of the East - Ramon Magsaysay Memorial Medical Center Inc.

2Department of Radiology

University of the East - Ramon Magsaysay Memorial Medical Center Inc.

${ }^{3}$ Department of Otorhinolaryngology Head and Neck Surgery

Jose R. Reyes Memorial Medical Center
Correspondence: Dr. Adrian F. Fernando Department of Otorhinolarynglogy Head and Neck Surgery

Rm. 463, Hospital Service Bldg., UERMMMCI

64 Aurora Blvd., Quezon City 1113

Philippines

Telefax: (632) 7161789

E-mail: ianfernando_md@yahoo.com

Reprints will not be available from the author.

The authors declared that this represents original material that is not being considered for publication or has not been published or accepted for publication elsewhere, in full or in part, in print or electronic media; that the manuscript has been read and approved by all the authors, that the requirements for authorship have been met by each author, and that each author believes that the manuscript represents honest work.

Disclosures: The authors signed disclosures that there are no financial or other (including personal) relationships, intellectual passion, political or religious beliefs, and institutional affiliations that might lead to a conflict of interest.

Presented at the Descriptive Research Contest, Philippine Society of Otolaryngology - Head and Neck Surgery, Glaxo Smith Kline (GSK) Bldg., Chino Roces Ave., Makati City, Philippines, October 11, 2010.

\title{
An Anatomical Study of the Cochlea among Filipinos using High-Resolution Computed Tomography Scans
}

\begin{abstract}
Objective: To describe the cochlear anatomy among Filipinos through high resolution computed tomography (HRCT) imaging.
\end{abstract}

\section{Methods:}

Design: Retrospective Study

Setting: Tertiary Private University Hospital

Patients: Cochlear images retrospectively obtained from computed tomography (CT) scans of subjects who underwent cranial, facial, paranasal sinus and temporal bone computed tomography from October 2009 to July 2010 were reconstructed and analyzed.

Results: 388 cochlear images were obtained from the scans of 194 subjects (101 males and 93 females, aged 1 to 90 years old, mean $=52$ years) and reconstructed for analysis. The mean coiled cochlear height measured $4.36 \mathrm{~mm}$ on the right (A.D.) and $4.34 \mathrm{~mm}$ on the left (A.S.). Measurement from the oval window to the distal end of the basal turn (equivalent to the horizontal dimension of the cochlea or the mean length of the basal turn) was $7.55 \mathrm{~mm}$ A.D. and $7.60 \mathrm{~mm}$ A.S. The vertical and horizontal dimensions of right and left cochleas were identical in all subjects (S.D. $=0.35$ ). The right and left cochlear turns were identical in each subject, exhibiting $2 \frac{1 / 2}{2}$ turns in $92.3 \%$ of subjects and $23 / 4$ turns in $7.7 \%$ of subjects. The cochlear dimensions were similar in all subjects, regardless of age. No cochlear ossification or malformation was noted on any $\mathrm{CT}$ image.

Conclusion: The $7.55 \mathrm{~mm}$ mean length of the cochlear basal turn among Filipinos in this study was $1.24 \mathrm{~mm}$ shorter than the average length of the basal turn of $8.81 \mathrm{~mm}$ reported elsewhere. Further studies of the cochlear dimensions in specific age groups and its correlation to audiometric status are recommended to determine other significant physiologic correlations.

Keywords: cochlea, cochlear turn, high-resolution computed tomography (HRCT), magnetic resonance imaging (MRI)

The cochlea and its anatomic details are difficult to study due to its minute size and remote location. It is surrounded almost entirely by dense bone of the otic capsule and has $2 \frac{1 / 2}{2}$ to $23 / 4$ coils. Before the advent of high resolution CT imaging, anatomical studies of the human cochlea 
were mostly cadaveric, making comprehension of human cochlear details and correlating histological findings with cochlear functional status more difficult. ${ }^{1}$ Today, computed tomography and magnetic resonance imaging can provide quality cochlear and temporal bone images indispensible in the practice of otology, but no local studies have been reported. Because further information and knowledge of cochlear dimensions among Filipinos is important especially in cochlear implantation, we aimed to describe the cochlear anatomy among Filipinos through high resolution computed tomography (CT) scan.

\section{METHODS}

Computed tomography (CT) scans of 194 subjects who underwent cranial, facial, temporal bone, paranasal sinus and orbital examinations for different indications between October 2009 to June 2010 at the University of the East - Ramon Magsaysay Memorial Medical Center were retrospectively obtained for temporal bone image isolation, in compliance with the hospital ethics committee. All scans used the same 64 detector-row Aquilon 64 (Toshiba Medical Systems Corp., Tokyo, Japan) employing 120 kV, 350 mA, $512 \times 512$ matrix dimension, $0.5 \mathrm{~mm}$ section thickness, 0.85 pitch and $70 \mathrm{~mm}$ field of view parameters. One hundred ninety four (194) temporal bone images with these parameters were obtained from 137 cranial, 24 temporal bone, 22 paranasal, 8 orbital, 2 facial and 1 mandibular scan(s) and were transferred to the Vitrea 2: version 4.1.20 (Vital images, Inc., Minnesota, USA) workstation for further image isolation. Multi-planar reconstruction (MPR) and 3D reconstruction of the cochlea were done with a 4000 window width and 700 window levels. Multi-planar reconstruction with double oblique coronal and single oblique settings were employed along the short and long axis of the cochlea as standard cochlear imaging. ${ }^{2}$ (Figure 1) Reconstructed cochlear images were trimmed and sculpted manually with the Vitrea 2 workstation for optimal 3D visualization.

The horizontal and vertical dimensions of each reconstructed coiled cochlea were measured with the Vitrea ${ }^{\circledR} 2$ workstation internal scale along its orthogonal views (Figure 2.A). The widest horizontal dimension of the coiled cochlea was measured on axial view from the highest point of the helicotrema to the inferior margin of the basal turn while the widest vertical dimension was measured on axial view from the oval window to the widest margin of the basal turn which is equivalent to the length of the cochlear basal turn (Figure 2.B). Conversely, the cochlear turn was measured on the axial-oblique view of the reconstructed cochlear image from the helecotrema to the round window (Figure 3). A line created through the reference point acted as the center of the modiolus and a complete cochlear turn was defined as the reference line run parallel to the basal and apical segments of the cochlea. ${ }^{3}$ Data gathered were tabulated for comparison of the vertical dimension, horizontal dimension and turns of the left and right cochlea. Presence or absence of cochlear deformities, ossification and other anomalies were also noted.

\section{RESULTS}

A total of 388 cochlear images were obtained from the CT scan images of 194 subjects (101 males and 93 females, aged 1 to 90 years, mean age $=52$ years) and reconstructed for analysis. The vertical dimension of the cochlea equivalent to the coiled cochlear height ranged from $3.30 \mathrm{~mm}$ to $5.10 \mathrm{~mm}$ on the right (mean $=4.37 \mathrm{~mm}$ ) and $3.40 \mathrm{~mm}$ to $5.20 \mathrm{~mm}$ on the left (mean $=4.34 \mathrm{~mm}$ ) with a difference of $0.02 \mathrm{~mm}$ (S.D. $=0.38, A D$ and $0.36, A S)$. The coiled cochlear widest dimension which is equivalent to the length of the basal turn ranged from $7.00 \mathrm{~mm}$ to $8.00 \mathrm{~mm}$ on the right (mean $=7.55 \mathrm{~mm}$ ) and $6.00 \mathrm{~mm}$ to $8.00 \mathrm{~mm}$ on the left (mean $=7.60 \mathrm{~mm}$ ) with a difference of $0.05 \mathrm{~mm}$ (S.D. $=0.33, A D$ and $0.36, A S$ ). The number of turns of the right and left cochlea in each of the subjects was identical, exhibiting $2 \frac{1}{2}$ turns in $92.3 \%$ of the subjects $(n=179)$ and $23 / 4$ turns in $7.7 \%$ of the subjects ( $n$ $=15$ ). The cochlear dimensions were similar in all subjects, regardless of age. No cochlear ossification or malformation was noted in any image.

\section{DISCUSSION}

Inner ear surgery has become more frequent and continues to advance over the past decade requiring otolaryngologists particularly neuro-otologists to have more detailed knowledge of cochlear anatomy. Detailed comprehension of the anatomy of the human cochlea has lagged behind that of other sensory systems because of technical difficulties in examining inner ear structures. Previous cadaveric model studies were time consuming, expensive and did not permit physiological correlation.

The mean length of the cochlea is about $33.01 \mathrm{~mm}$ (S.D. $2.31 \mathrm{~mm})^{4}$ and is normally known to demonstrate $2 \frac{1}{2}$ to $23 / 4$ turns to allow its full dimensions to be accommodated in the temporal bone. A study comparing eight adult cochleas with eighteen formalin-fixed fetal specimens at the Carnegie Embryological Collection of normal fetuses using plain radiography, computed tomography (CT) and magnetic resonance (MR) imaging showed that the mean length of the cochlear basal turn is $7.86 \mathrm{~mm}$ and $8.81 \mathrm{~mm}$ in the fetal and adult subjects respectively which is $0.29 \mathrm{~mm}$ to $1.24 \mathrm{~mm}$ longer than the cochlear basal turn length noted in this study. ${ }^{5}$

In the present local clinical setting, CT and MRI are the imaging modalities used for assessing the cochlea, with MRI as the imaging method of choice for assessing the spiral canal, especially in cochlear implant candidates. ${ }^{6}$ However, recent improvements in $\mathrm{CT}$ imaging 


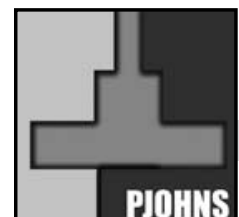

ORIGINAL ARTICLES

Philippine Journal Of Otolaryngology-Head And Neck Surgery

Vol. 26 No. 1 JANUARY - JunE 2011
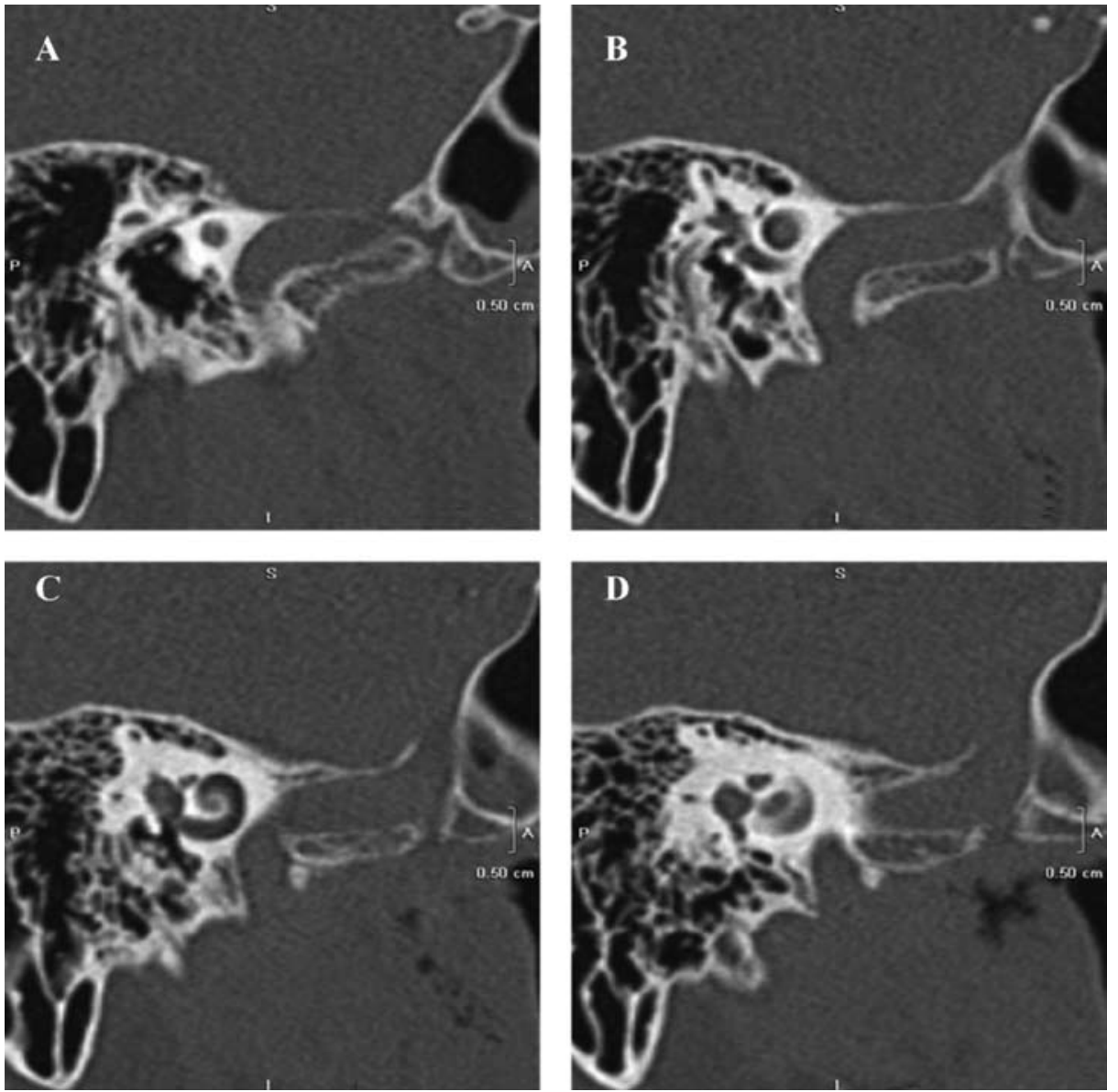

Figure 1. Double oblique coronal view of the R temporal bone showing the cochlear dimensions. A. apical turn; B. middle turn C. basal turn. D. cochlear base
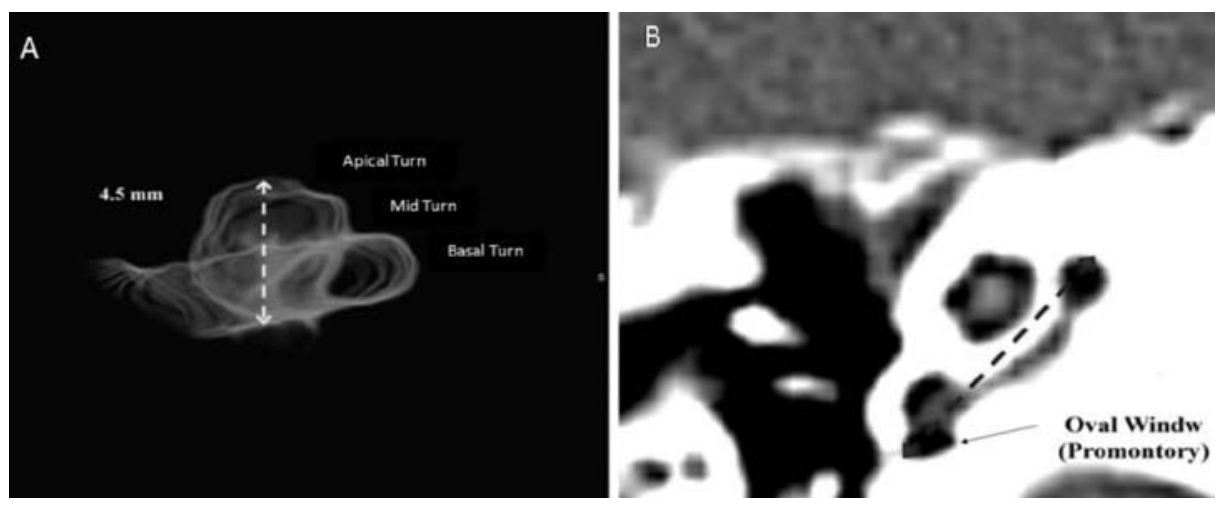

Figure 2. Measurement of the coiled cochlear dimensions. A. Orthogonal view of the $3 D$ reconstructed cochlea showing the measurement of the coiled cochlear vertical dimension from the helicotrema to the lowest margin of the basal turn. B. Coronal view of the cochlea showing the measurement of the coiled cochlear horizontal dimension from the promontory to the most lateral portion of the basal turn. 


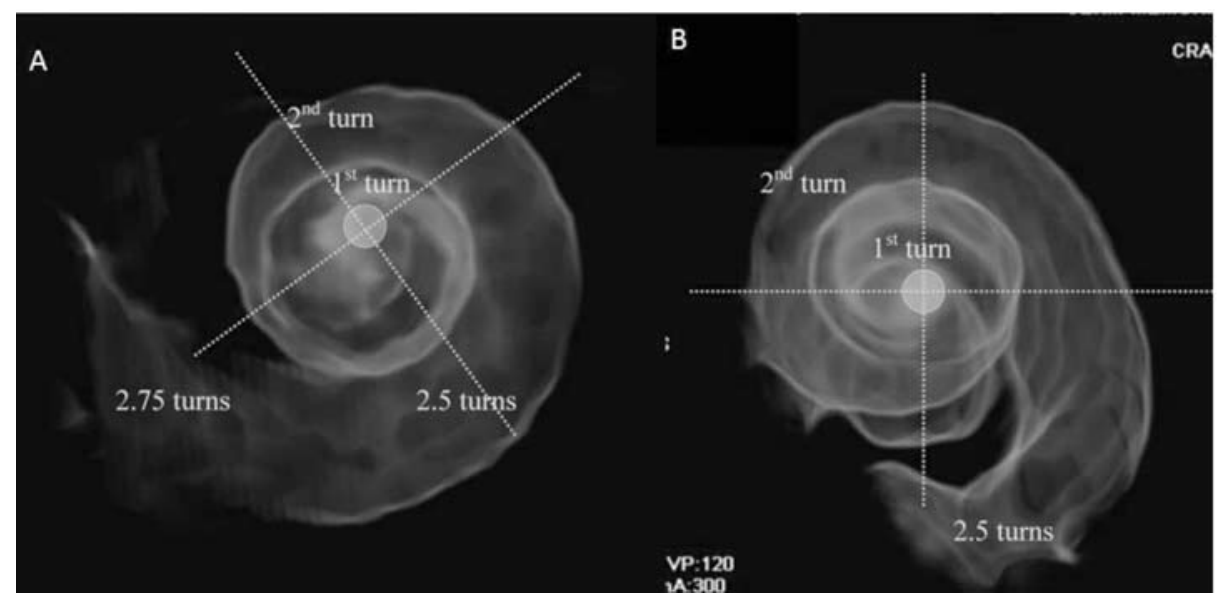

Figure 3. Measurement of the cochlear turns through the 3D reconstructed cochlea. Cochlea with A. $2 \frac{3 / 4}{4}$ turns and B. $2 \frac{1}{2} 2$ turns.

technology may now facilitate visualization of the inner ear at resolutions sufficient to assess the basic structural anatomy of the coiled cochlea at lower costs than MRI providing opportunities to validate existing knowledge on human cochlear dimensions, turns, details, variations and anomalies. Recent anatomical studies of the human cochlea with CT scans have also increased recognition of inner ear malformations in subjects with normal hearing and in those with hearing impairment. ${ }^{7}$

The use of high-resolution CT in studying the cochlear anatomy is a feasible and relatively inexpensive means that may be correlated with other functional or audiometric studies and experiments, an aspect that is difficult to match with cadaveric cochlear studies. The measurements of coronal cochlear height and other bony inner ear structures particularly the lateral semicircular canal have excellent reproducibility and sensitivity in detecting inner ear malformations. ${ }^{8,9}$ High-resolution CT also avoids image artifices with an acquisition of submillimetrical slices with optimum resolution ${ }^{10}$ and may be valuable in the advancement of cochlear implantation and engineering future implants. ${ }^{11}$

It is recommended that in future studies, the age and audiometric status be stratified and classified for better correlation with the minute inner ear structures and to minimize systemic biases. ${ }^{12}$ Further studies with better comparison of the cochlear dimensions in specific age groups and its correlation to audiometric status are recommended to determine other significant physiologic correlations.

\section{REFERENCES}

1. Manoussaki D, Chadwick RS, Ketten DR, Arruda J, Dimitriadis EK, O'Malley JT. The Influence of Cochlear Shape on Low-Frequency Hearing. Proc Natl Acad Sci U S A. 2008 Apr 22;105(16):6162-6. Epub 2008 Apr 14.

2. Lane Jl, Lindell EP, Witte RJ, DeLone DR, Driscoll CL. Improved Depiction with Multiplanar Reconstruction of Volumetric CT Data. Radiographics. 2006 Jan-Feb; 26(1):115-24.

3. Rebscher SJ, Hetherington A, Bonham B, Wardrop P, Whinney D, Leake PA. J Rehabil Res Dev. 2008;45(5):731-47.

4. Takagi A, Sando I. Computer-Aided Three-Dimensional Reconstruction: A Method of Measuring Temporal Bone Structures Including the Length of the Cochlea. Ann Otol Rhinol Laryngol. 1989 Jul;98(7 Pt 1):515-22.

5. Nemzek WR, Brodie HA, Chong BW, Babcook CJ, Hecht ST, Salamat S, et al. Imaging Findings of the Developing Temporal Bone in Fetal Specimens. AJNR Am J Neuroradiol. 1996 Sep;17(8):1467-77.

6. Baumgartner WD, Youssefzadeh S, Hamzavi J, Czerny C, Gstoettner W. Clinical Application of Magnetic Resonance Imaging in 30 Cochlear Implant Patients. Otol Neurotol. 2001 Nov;22(6):818-22.

7. Purcell D, Johnson J, Fischbein N, Lalwani AK. Establishment of normative cochlear and vestibular measurements to aid in the diagnosis of inner ear malformations. Otolaryngol Head Neck Surg. 2003 Jan;128(1):78-87.

8. Purcell DD, Fischbein NJ, Patel A, Johnson J, Lalwani AK. Two temporal bone computed tomography measurements increase recognition of malformations and predict sensorineural hearing loss. Laryngoscope. 2006 Aug;116(8):1439-46.

9. Lan MY, Shiao JY, Ho CY, Hung HC. Measurements of normal inner ear on computed tomography in children with congenital sensorineural hearing loss. Eur Arch Otorhinolaryngol. 2009 Sep;266(9):1361-4. Epub 2009 Feb 24.

10.Mallo WM, Giordanengo C, Bertona C, Bertona JJ, Gigena C, Florez MP. Ear study with 64 slices Multidetector CT. The International Society of Radiology [serial on the Internet] 2010 [cited 2010 February 4]; 74(4): [about 7 p.] Available from: http://isradiology.org/ gorad/docs/rard_art_oido_en.pdf.

11.Bogar M, Bento RF, Tsuji RK. Cochlear anatomy study used to design surgical instruments for cochlear implants with two bundles of electrodes in ossified cochleas. Braz J Otorhinolaryngol. 2008 Mar-Apr;74(2):194-9.

12. Chen JL, Gittleman A, Barnes PD, Chang KW. Utility of temporal bone computed tomographic measurements in the evaluation of inner ear malformations. Arch Otolaryngol Head Neck Surg. 2008 Jan;134(1):50-6. 